\title{
Ancient human ancestor had feet like an ape
}

Fossil foot hints that tree-dwellers lived alongside species built for walking.

\section{Brian Switek}

28 March 2012

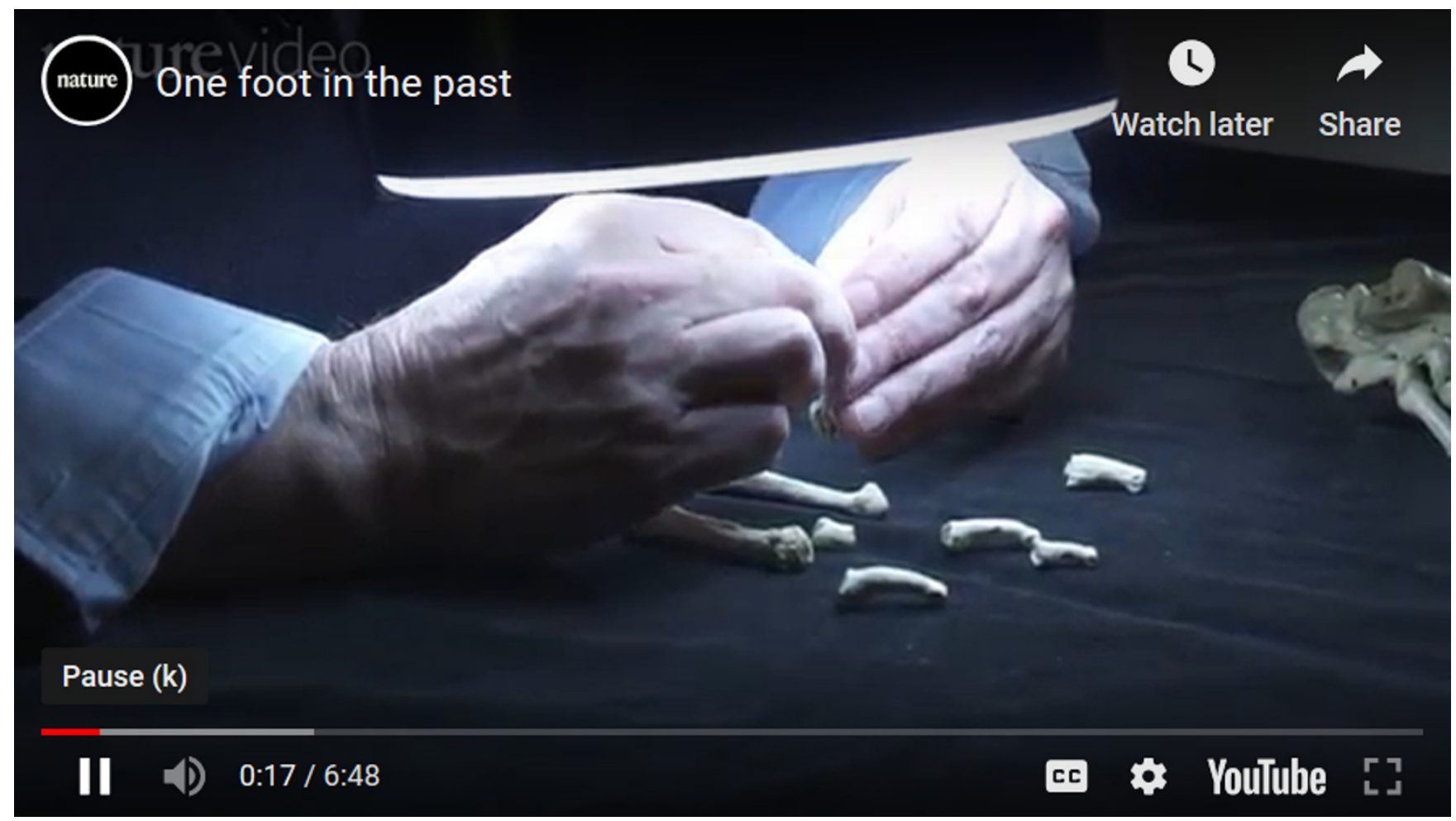

A fossil discovered in Ethiopia suggests that humans' prehistoric relatives may have lived in the trees for a million years longer than was previously thought.

The find may be our first glimpse of a separate, extinct, branch of the human family, collectively called hominins. It also hints that there may have been several evolutionary paths leading to feet adapted for walking upright.

The fossil, a partial foot, was found in 3.4-million-year-old rocks at Woranso-Mille in the Afar region of Ethiopia. Bones of the hominin Australopithecus afarensis - the species to which the famous 'Lucy' skeleton belongs — have also been found in this location and from the same period.

But unlike $A u$. afarensis, the latest find has an opposable big toe — rather like a thumb on the foot — that would have allowed the species to grasp branches while climbing. Modern apes have similar toes, but the youngest hominin previously known to have them is Ardipithecus ramidus, which lived about 4.4 million years ago. The details of the discovery are published today in Nature ${ }^{1}$.

$A u$. afarensis has a big toe that is more closely aligned with the other digits on the foot, an adaptation that provides support during upright walking. Au. afarensis "was fully bipedal and had already abandoned life in the trees", says study author Yohannes HaileSelassie of the Cleveland Museum of Natural History in Ohio, whereas the newly discovered creature had not seemingly committed to life on the ground.

Other features of the fossil foot show that it did not belong to an ape, but that it is truly a member of the hominins, says Haile-Selassie. The latest specimen is "very much like the Ardipithecus foot, which I believe had many hominin features, so it's likely to be a hominin", agrees Daniel Lieberman, an anthropologist at Harvard University in Cambridge, Massachusetts, who was not involved in the study.

\section{Good grasp of history}

The discovery shows that one hominin lineage had grasping feet for at least a million years after Ar. ramidus. The creature was 
probably more agile in the trees than $\mathrm{Au}$. afarensis but less nimble on two feet, says William Harcourt-Smith, an anthropologist at the City University of New York's Lehman College. "We can only get a tantalizing glimpse at this, but its bipedal gait is likely to have been very different from Lucy's and was probably a lot less efficient," he says.

The finding will force a rethink regarding the course of early hominin evolution, Harcourt-Smith adds. The addition of a mystery hominin species at this crucial time period suggests that the new species' lineage split from that leading to Lucy earlier in hominin history, and provides further evidence against the idea that modern humans evolved via a linear progression of species from apes. "This [finding] is fascinating, and makes the evolution of this defining behaviour not a single, linear evolutionary event, but a far more complex affair," Harcourt-Smith says.

Nature | doi:10.1038/nature.2012.10342

\section{References}

1. Haile-Selassie, Y. et al. Nature 483, 565-569 (2012). 